\title{
Ein neuer Pumpapparat für Infusion, Punktion, Transfusion usw*
}

\author{
Von \\ Yoshinobu Wada. \\ （和 田 義 信） \\ (Aus der Chirurgischen Klinik der Tohoku-Reichsuniversität, \\ Sendai. Direktor: Prof. Dr. Sh. Sekiguchi.)
}

Ich stellte einen neucn Apparat für Infusion, Punktion, Transfusion usw. her, den man ohne Helfer handhaben kann, und leicht tragbar und sterilisierbar ist, über dessen Bau ich hier berichten möchte.

Der Apparat besteht aus einer Pumpe aus Metall und aus einem hitzfesten Gummischlauch.

Fig. 1 zeigt ein Modell des wichtigsten Teils meines Apparats. (A) ist eine Schraubenspindel, die auf einem durch einen Griff drehbaren Zylinder

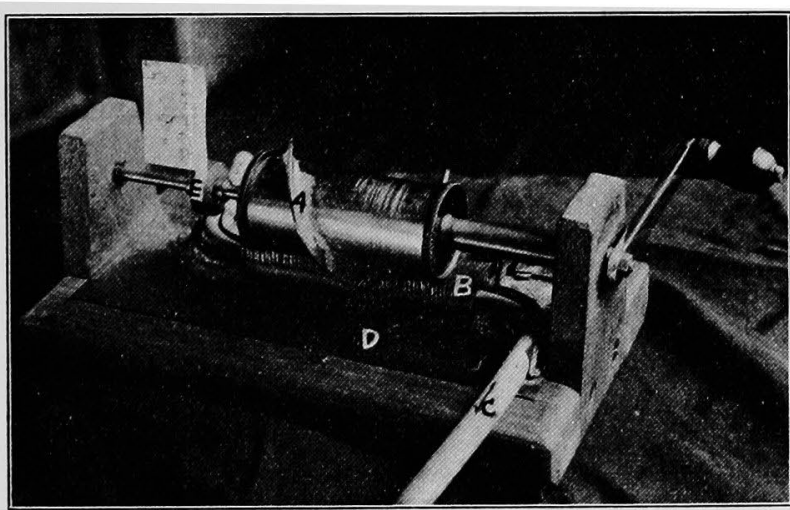

Fig. 1.

sitzt. (B) ist eine grosse Anzahl nebeneinander aufrecht stehender Metallplättchen von gleicher Höhe, Länge und Dicke, deren eines Ende mit einer Achse zusammenhängt. (C) ist ein Gummischlauch von einem Durchmesser, der kleiner ist, als die Schlaube (A) hoch ist, und der in die S-förmige Rinne auf dem Untersatz (D) ge-

* Patent in Japan, England, U.S.A., Frankreich und Deutschland. 
legt wird. (A), (B), (C) und (D) sind in einem bestimmten Abstand voneinander gehalten.

Nun zur Tätigkeit dieses Apparats: (A) presst (C) durch Vermittlung von (B), bis an einer oder zwei Stellen von (C) der Innenraum vollständig verschlossen ist. Wenn man die Achse des Zylinders in bestimmter Richtung dreht, so wird jedes einzelne Blättchen von (B) in bestimmter Ordnung niedergedrückt, wodurch der Teil, $\operatorname{der}(\mathrm{C})$ hinabdrückt, wiederholt hin und her bewegt wird.

(C) saugt die Flüssigkeit oder das Gas automatisch durch seine Elastizität, wodurch der Inhalt in (C) vorwärts befördert wird, wenn man (A) umdreht.

Wenn man eine Hohlnadel an die Ausflussmündung von (C) befestigt, dann kann man die Flüssigkeit injizieren oder infundieren; wenn man sie an die Einflussmündung bringt, kann man aufsaugen.

Die Menge der Flüssigkeit, die durch einmalige Umdrehung von (A) in (C) gesandt wird, ist konstant und entspricht dem Durchmesser von $(\mathrm{C})$.

Man kann den Innendruck im Ausführungsschenkel von (C) dadurch entsprechend verstärken, dass man die Entfernung zwischen (A) und (D) entsprechend verändert.

Mehrere Blättchen von (B) drücken einen oder zwei Teile von (C) sicher hinab, wodurch die Flüssigkeit durchaus nicht mehr zurückfliessen kann.

Die Menge der Flüssigkeit, die durch einmalige Drehung von (A) in (C) eingeführt wird, ist konstant, ohne Rücksicht auf den Innendruck des Ausflussschenkels von (C).

(E) ist ein Gummiring auf der Rotationsachse von (A), der mit einem Zeiger verbunden ist. Fig. 2 zeigt die für den wirklichen Gebrauch fertige For'm, Fig. 3 das Innere von Fig. 2.

$I$ ist ein Metallkasten, in $\operatorname{dem} A, B$ und der Zeigerapparat montiert sind. II ist

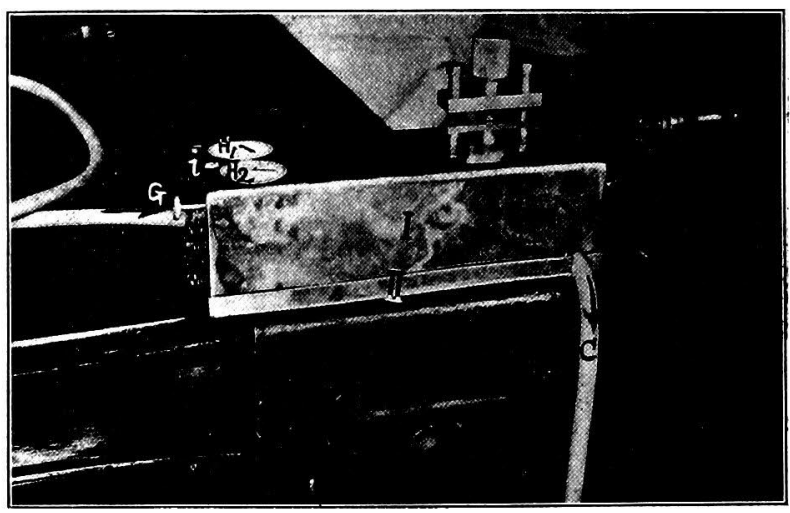

Fig. 2. 
auch ein Metallkasten, der dem Deckel von I entspricht; in ihm ist eine Sförmige Rinne, in die der Gummischlauch (C) zu legen ist, und darunter ist eine Klammerschraube, mit der der Kasten leicht am Rand

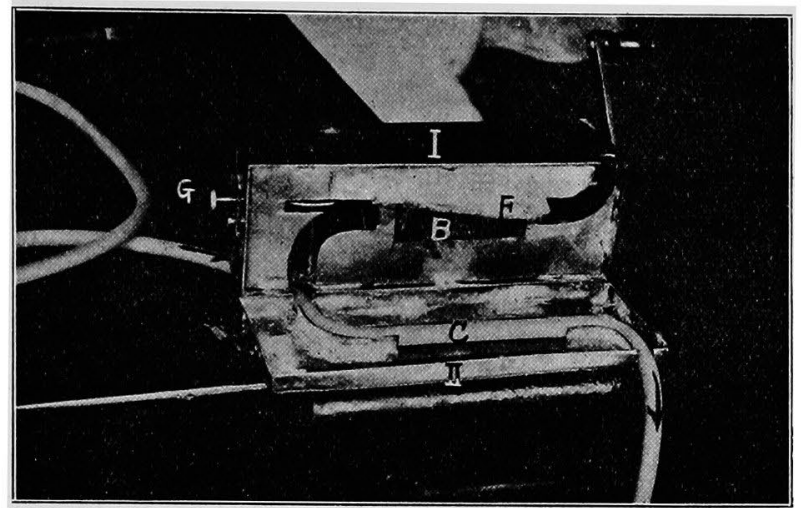

Fig. 3. eines Tisches befestigt werden kann. festigt.

Beim Gebrauch wird I auf II durch Scharnier und Schnalle be-

(F) ist ein Vorhang von Leinwand oder Leder, wodurch der Gummischlauch geschützt wird.

(G) ist eine Schraube, die die wirkliche Menge der aus dem Apparat ausfliessenden Flüssigkeit und der vom Zeiger gezeigten im voraus experimentell recht anzeigen lässt.

$\mathrm{H}_{1}$ und $\mathrm{H}_{2}$ sind Gradmesser, bei denen ein Grad von $\mathrm{H}_{1} 1 \mathrm{ccm}$ und einer von $\mathrm{H}_{2} 10$ ccm entspricht. (i) ist der Knopf, durch dessen Druck der Zeiger zum Nullpunkt zurückkehrt.

Jetzt schildere ich nun die Handhabung dieses Apparats, und zwar zuerst bei der Infusion.

Man fixiert II am Tischrand mit der Klammerschraube, legt den Gummischlauch mit dem Verbindungsrohr und der Nadel, die beide vorher desinfiziert worden sind, in die Rinne hinein.

Man fixiert nun I mit Scharnier und Schnalle auf II.

Man legt den Einführungsschenkel des Gummischlauchs in die gewünschte Flüssigkeit. Dann dreht man den Griff, bis der Schlauch leer von Luft ist, und ist der Apparat fertig zum Arbeiten.

Man sticht die Nadel in die betreffende Stelle und lässt den Zeiger zum Nullpunkt zurückkehren, durch einen Druck des Fingers auf (i).

Die folgende Drehung des Griffs lässt die Flüssigkeit in den betreffenden Teil fliessen, und die Zeiger zeigen die infundierte Menge fehlerfrei an.

Bei der Punktion wird die Nadel, die an dem Einführungsschenkel des Gummischlauchs befestigt ist, von Anfang an in die betreffende Stelle gestochen. 
Bei direkter Bluttransfusion wird der Schlauch vorher mit physiologischer Kochsalzlösung gefüllt und der auf- und der absteigende Schenkel des Schlauchs mit Klemme fest geschlossen.

Man sticht die Ausführungsnadel in die Vena centralis cubiti des Kranken und nimmt die Klemme weg, dann wird das Blut in das Verbindungsrohr stürzen.

Man sticht ähnlich in die Vena centralis cubiti des Spenders und drückt auf den Knopf $i$, dann ist die Vorbereitung fertig.

Wenn die gewünschte Transfusion beendet ist, legt man die Einführungsnadel, die beim Spender herausgenommen worden ist, wieder in physiologische Kochsalzlösung und dreht den Griff wieder, wodurch das im Schlauch zurückgehaltene Blut in den Empfänger gelangt.

Bei direkter Bluttransfusion darf der Gummischlauch nicht länger als $75 \mathrm{~cm}$ sein und der Griff muss ohne Unterbrechung gedreht werden, damit das Blut im Schlauch nicht koaguliert.

Kurz noch einmal, mein Apparat ist klein, deshalb bequem zu tragen. Der Bau fest, er ist ganz leicht zu desinfizieren und zu handhaben, er arbeitet sicher und ist zu verschiedenen Zwecken zu verwenden. 